\title{
Comunicação
}

[Communication]

\section{Sarcoma sinovial extra-articular em cão}

\author{
[Extra-articular synovial sarcoma in a dog] \\ S.A. França, R. Serakides*, A.E. Silva, M.A. Rachid, J.R.C. Moraes, G.E. Lavalle, N.M. Ocarino \\ Escola de Veterinária - UFMG \\ Caixa Postal 567 \\ 30123-970 - Belo Horizonte, MG
}

O sarcoma sinovial é uma neoplasia maligna caracterizada pela presença de células mesenquimais e/ou epiteliais (Vail et al., 1994). A localização extra-articular raramente é relatada (Pool e Thompson, 2002) e as características imunoistoquímicas não têm sido estudadas nos sarcomas sinoviais dos animais domésticos. A literatura não cita predileção por raça, sexo ou idade para a ocorrência dessa neoplasia. Contudo, cães de grande porte e machos com idades entre 5 e 15 anos são mais freqüentemente acometidos (Pool, 1990). Metástases podem estar presentes nos pulmões, baço e linfonodos (Reed et al., 1978; Mitchell e Hurov, 1979; Griffith et al., 1987).

A sinóvia pode ser encontrada revestindo as estruturas articulares e as bainhas dos tendões. Dois tipos de células são reconhecidos: o tipo A, representado por células originadas da medula óssea que migram para a articulação cuja função principal é a fagocitose, e o tipo $\mathrm{B}$, que compõe 70 a $80 \%$ das células sinoviais, com características de células mesenquimais, responsáveis pela produção de líquido sinovial e de matriz extracelular. Histologicamente o sarcoma sinovial é classificado em bifásico, caracterizado pela presença de células epiteliais dispostas em padrão pseudo-glandular e de células mesenquimais semelhantes a fibroblastos, e monofásico, no qual predomina epitélio ou mais freqüentemente mesênquima (Leader et al., 1987).
O objetivo do presente relato é descrever e discutir os achados anatomopatológicos e imunoistoquímicos de um caso de sarcoma sinovial extra-articular em uma cadela Collie de quatro anos de idade, atendida no Hospital Veterinário da Universidade Federal de Minas Gerais. O animal apresentava aumento de volume de crescimento lento, com aproximadamente $15 \mathrm{~cm}$ de diâmetro e de consistência macia localizado no subcutâneo da região lateral da coxa esquerda, próximo à articulação fêmuro-tíbio-patelar.

Ao exame radiológico não se observou comprometimento da articulação que apresentava todas as estruturas bem delimitadas e com radiopacidade uniforme. O líquido sinovial também não mostrou alteração significativa. Foi realizada a exérese cirúrgica da massa que estava bem delimitada, não invasiva, localizada somente no subcutâneo e que, ao corte, era esbranquiçada, com aspecto lobular, com áreas amarronzadas, friáveis e com hemorragias multifocais.

Vários fragmentos da massa, fixados em formalina a $10 \%$ neutra e tamponada, foram processados pela técnica rotineira de inclusão em parafina e de coloração pela hematoxilina-eosina. Fragmentos da neoplasia também foram submetidos à análise imunoistoquímica utilizando-se os seguintes marcadores nas diluições apropriadas: antivimentina, anti-citoqueratinas AE1 e AE3, antiproteína $\mathrm{S}-100$, anti-alfa-actina de músculo liso,

Recebido para publicação em 29 de julho de 2003

Recebido para publicação, após modificações, em 25 de agosto de 2004

*Autor para correspondência

E-mail: serakide@dedalus.lcc.ufmg.br

Arq. Bras. Med. Vet. Zootec., v.56, n.5, p.683-686, 2004 
anti-CD-34 e proteína do sarcoma de Ewing ${ }^{1}$. O complexo estreptavidina-biotina-peroxidase ${ }^{2}$ e a diaminobenzidina $^{3}$ foram utilizados para detecção dos antígenos. Secções foram contra-coradas com hematoxilina de Harris.

À microscopia observou-se na hipoderme uma massa multilobar e cística formada por lóbulos de tamanhos variados, separados por finas trabéculas de tecido conjuntivo (Fig. 1A), contendo área central de necrose, focos hemorrágicos e acúmulo de material fibrinóide. Esses lóbulos formavam vilosidades em direção ao lúmen, eram compostos por numerosas células poligonais e, em algumas áreas, por grupos de células alongadas pleomórficas. As células poligonais apresentavam núcleos arredondados a ovais, vesiculosos, com nucléolos múltiplos e proeminentes. O citoplasma era abundante, espumoso, com quantidades variáveis de material granular eosinofílico. Observaram-se ainda, anisocitose e anisocariose acentuadas e algumas células gigantes e bizarras (Fig. 1B). Figuras mitóticas eram raras. Alguns agregados pequenos de plasmócitos e linfócitos foram visualizados entre os lóbulos e na base da massa tumoral. A derme adjacente possuía proliferação focal de tecido conjuntivo denso, contendo vasos dilatados e acúmulo de hemossiderófagos. Alguns critérios histológicos como invasibilidade, pleomorfismo nuclear, índice mitótico, número de nucléolos, de células gigantes e multinucleadas e proporção necrose/tumor foram observados. $\mathrm{O}$ escore obtido pelo somatório desses critérios permite a graduação histológica da neoplasia, que pode variar de I (melhor prognóstico) a III (pior prognóstico). Na neoplasia estudada estabeleceu-se o grau II.

A imunoistoquímica revelou expressão forte $\mathrm{e}$ difusa de vimentina (Fig. 1C) e marcação citoplasmática moderada e multifocal de citoqueratinas AE1 e AE3 (Fig. 1D). Não foi evidenciada nenhuma expressão de alfa-actina de músculo liso, proteína do sarcoma de Ewing, proteína S-100 e de CD-34.

Os sarcomas sinoviais não apresentam histogênese conhecida (Leader et al., 1987), sendo observados em regiões periarticulares e em sítios onde inexiste sinóvia (Dardick et al., 1991). No presente caso a localização indica que a neoplasia originou-se na bainha do tendão do músculo vasto lateral.

\footnotetext{
Dako, USA

${ }^{2}$ Streptavidin Peroxidase, Lab Vison

${ }^{3}$ DAB- Substrate System, Lab Vision
}

As características histológicas observadas foram semelhantes àquelas descritas na literatura para sarcomas sinoviais em cães (Reed et al., 1978; Lipowitz et al., 1979; Griffith et al., 1987). A exemplo do que foi observado por Vail et al.(1994) em 36 sarcomas sinoviais, a graduação histológica se mostrou importante fator prognóstico na evolução clínica e no tratamento da neoplasia. Após um ano da exérese cirúrgica a cadela não apresentou recidivas e nenhuma outra alteração digna de nota.

O perfil imunoistoquímico dos sarcomas sinoviais bifásicos na espécie humana revela expressão de citoqueratinas, antígeno epitelial de membrana (EMA) e de vimentina e ausência de marcação do antigeno carcinoembrionário e de CD-34 (Dardick et al., 1991). Pode também haver expressão da proteína S-100 (Pool e Thompson, 2002). Miettinen (2000) verificaram maior expressão de citoqueratinas nos sarcomas sinoviais bifásicos e menor expressão naqueles pobremente diferenciados. A coexpressão de citoqueratinas e vimentina na neoplasia estudada revela seu caráter bifásico, facilitando o diagnóstico, tendo em vista que o sarcoma sinovial monofásico é facilmente confundido com outros sarcomas (Pool, 1990), sendo às vezes necessário o estudo citogenético ou de biologia molecular para firmar o diagnóstico definitivo (Miettinen, 2000).

É importante salientar que a classificação inicial de sarcoma sinovial na literatura baseou-se no fato de as células neoplásicas serem morfologicamente semelhantes aos sinoviócitos. Contudo, existem evidências estruturais e imunoistoquímicas de que essa neoplasia não deriva da sinóvia (Miettinen e Virtanen, 1984; Leader et al., 1987). Ao contrário dos sinoviócitos, as células neoplásicas estão arranjadas sobre uma membrana basal e possuem tight junctions, apresentando marcação não apenas para vimentina mas também para citoqueratinas. Assim, o termo sarcoma sinovial é inadequado, sendo mais pertinente a denominação de carcinossarcoma.

Com base nos achados anatomopatológicos e imunoistoquímicos foi firmado o diagnóstico de sarcoma sinovial extra-articular bifásico de grau II.

Palavras-chave: cão, neoplasia, sarcoma sinovial, imunoistoquímica 

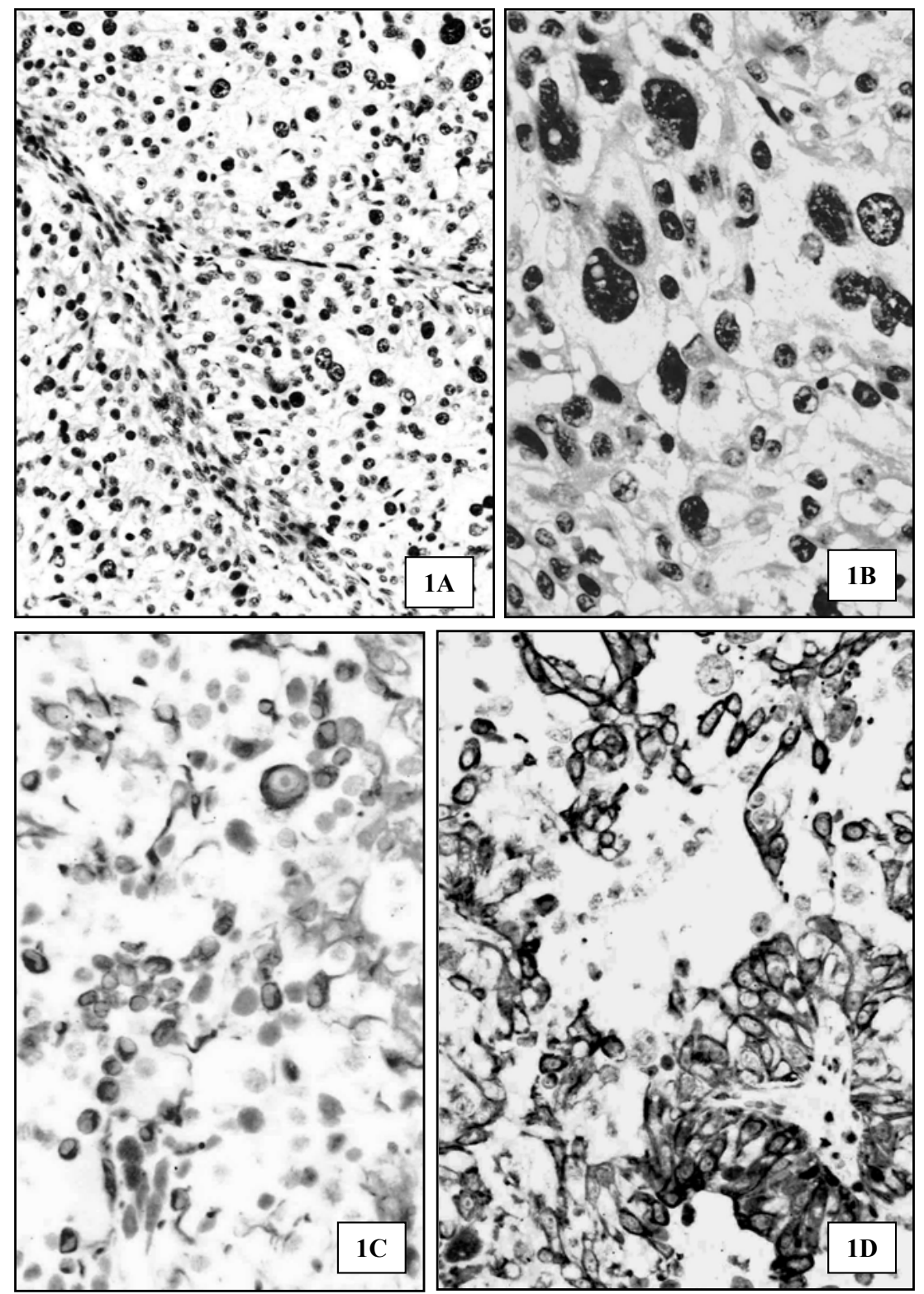

Figura 1. Sarcoma sinovial, cão. (A) Células dispostas em lóbulos separados por delgado conjuntivo, HE, 214,3×. (B) Células neoplásicas poligonais com núcleos arredondados a ovais, vesiculosos, contendo nucléolos múltiplos, proeminentes e citoplasma abundante e espumoso. Observam-se também algumas células gigantes e bizarras. HE, 428,6×. (C) Citoplasma das células neoplásicas com imunomarcação forte para vimentina. Estreptavidina-biotina-peroxidase, hematoxilina de Harris, 428,6×. (D) Citoplasma das células neoplásicas com imunomarcação forte para citoqueratina AE1/AE3. Estreptavidina-biotinaperoxidase, hematoxilina de Harris, 428,6×. 


\begin{abstract}
One four-year-old, female, Collie, dog presented subcutaneous enlarged mass at the lateral aspect of the left hindlimb, close to the knee joint. Based on the anatomopathological and immunohistochemical findings it was confirmed the diagnosis of extra-articular bifasic synovial sarcoma-grade II.
\end{abstract}

Keywords: dog, neoplasia, synovial cell sarcoma, immunohistochemistry

\section{REFERÊNCIAS BIBLIOGRÁFICAS}

DARDICK, I; RAMJOHN, S.; THOMAS, M.J. et al. Synovial sarcoma - Inter-relationship of the biphasic and monophasic subtypes. Pathol. Res. Pract., v.187, p.871-885, 1991.

GRIFFITH, J.M.; FREY, R.A.; SHARKEY, F.E. Synovial sarcoma of the jaw in a dog. J. Comp. Pathol., v.97, p.361-364, 1987.

LEADER, M.; MRCPATH, M.D.; PATEL, J. et al. Sinovial sarcomas true carcinosarcomas? Cancer, v.59, p.2096-2098, 1987.

LIPOWITZ, A.L.; FETTER, A.W.; WALKER, M.A. Synovial sarcoma of the dog. J. Am. Vet. Med. Assoc., v.174, p.76-81, 1979.

MIETTINEN, M.; Patterns of keratin polypeptides in 110 biphasic, monophasic, and poorly differentiated synovial sarcomas. Virchows Arch., v.437, p.275-283, 2000.
MIETTINEN, M.; VIRTANEN, I. Synovial sarcoma - a misnomer. Am. J. Pathol. , v.117, p.18-25, 1984.

MITCHELL, M.; HUROV, L.I. Synovial sarcoma in dog. J. Am. Vet. Med. Assoc., v.174, p.53-55, 1979.

POOL, R.R. Tumors and tumours like lesions of joints and adjacent soft tissues. In: MOULTON, J.E. (Ed.). Tumors in domestic animals. 3.ed. Berkeley: University of California, 1990. P.102156.

POOL, R.R.; THOMPSON, K.G. Tumors of joints. In: MEULTEN, D.J. (Ed.). Tumors in domestic animals. 4.ed. Iowa: Iowa State, 2002. P.199-243.

REED, J.R.; WELLER, R.E.; HORNOF, W.J. Synovial sarcoma in a dog. Mod. Vet. Pract., v.59, p.605-608, 1978.

VAIL, D.M.; POWERS, B.E.; GETZY, D.M. Evaluation of prognostic factors for dogs with synovial sarcoma: 36 cases (1986-1991). J. Am. Vet. Med. Assoc., v.205, p.1300-1307, 1994. 